\title{
COMPARISON OF MINI-MENTAL STATE EXAMINATION (MMSE) AND BANGLA MINI-MENTAL STATE EXAMINATION (MMSE-B) AMONG HEALTHY ELDERLY IN BANGLADESH
}

\author{
GHOSE SK ${ }^{1}, \mathrm{CHOWDHURY} \mathrm{AH}^{2}$, HASAN ATMH ${ }^{3}, \mathrm{KHAN} \mathrm{MZR}^{4}, \mathrm{KARIM} \mathrm{ASMR}^{5}$, SAHA K ${ }^{6}, \mathrm{HABIB} \mathrm{M}^{7}$, \\ HOQUE MA ${ }^{8}$, ALAM MB ${ }^{9}$, MOHAMMAD QD ${ }^{10}$
}

\begin{abstract}
Objective: The aim of the present study was to compare the efficacy of modified Bangla version of mini mental state examination (MMSE-B) with mini mental state examination (MMSE) for using among Bangladeshi healthy elderly.

Methods: This is a descriptive type of observational study carried out in Department of Neurology, Dhaka Medical College Hospital, Dhaka, from January to December of 2013. A total of 200 healthy elderly (patient attendants at the clinic) who met the inclusion criteria, were interviewed using a structured questionnaire containing information on age, sex, residence, educational backgrounds and questions set at MMSE English version (MMSE-E) and modified Bangla version for MMSE-B (Figure-1). MMSE and MMSE-B both were applied in 1:1 ration. The literate people were asked whether they are comfortable to answer in English (MMSE-E) or they would like the translated form and we applied the form of MMSE (MMSE-T) according to their wish. But in other group of people the modified Bangla version (MMSE-B) was used irrespective of level of education.

Results: The mean age at presentation was $58.1 \pm 7.8$ and $94 \%$ were within $50-70$ years of age. Male were more common $(80,66)$ in both the groups and most of them belonging to rural areas. MMSE-B were mostly employed on people having only primary level of education (up to class five, $n=80$ ) or no education ( $n=2)$, whereas MMSE-E were employed up on people having a level of education higher than class five $(n=96)$. Every question in each item of cognitive domain correlated well (correlation co-efficient range from 0.801-0.971) except the $7^{\text {th }}$ (correlation co-efficient 0.418) which had higher mean score for MMSE-B than those of MMSE-E (O.9O versus 0.54$)$. The mean score of MMSE-B was greater than the mean score of MMSE-E for most of questions except the $1^{\text {st }}$ question that is related to orientation of time. The mean of total score in MMSE-E and MMSE-B were 24.04 and 24.91 respectively with a correlation co-efficient of 0.940 .
\end{abstract}

Conclusion: MMSE-B is comparable to MMSE and it is even better in some segments of cognitive assessment for using among Bangladeshi people irrespective of level of education.

Key words: Mental health, mental state, modified Bangla version of mini mental state examination (MMSE-B), mini mental state examination (MMSE), Bangladeshi people.

J Dhaka Med Coll. 2015; 24(1) : 30-35.

1. Dr. Swapon Kumar Ghose, Associate Professor, Department of Neurology, Dhaka Medical College, Dhaka.

2. Dr. Ahmed Hossain Chowdhury, Assistant Professor, Department of Neurology, Dhaka Medical College, Dhaka.

3. Dr. ATM Hasibul Hasan, Indoor Medical Officer, Department of Neurology, Dhaka Medical College Hospital, Dhaka.

4. Dr. Muhammad Zillur Rahman Khan, Assistant Professor, Department of Child and Adolescent Psychiatry, National Institute of Mental Health and Hospital, Dhaka.

5. Dr. ASM Rezaul Karim, Senior Consultant (Medicine), Nilphamari Sadar Hospital, Nilphamari.

6. Dr. Kanol Saha, Registrar, Department of Neurology, Dhaka Medical College Hospital, Dhaka.

7. Prof. Mansur Habib, Professor, Department of Neurology, Dhaka Medical College, Dhaka.

8. Prof. Md. Azharul Hoque, Professor, Department of Neurology, National Institute of Neurosciences and Hospital, Dhaka.

9. Prof. Md. Badrul Alam, Professor, Department of Clinical Neurology, National Institute of Neurosciences and Hospital, Dhaka.

10. Prof. Quazi Deen Mohammad, Professor and Director, National Institute of Neurosciences and Hospital, Dhaka. Correspondence: Dr. ATM Hasibul Hasan, Indoor Medical Officer, Department of Neurology, Dhaka Medical College Hospital, Dhaka. Email: parag007us@gmail.com 


\section{Introduction:}

The global life expectancy of individuals in Bangladesh has significantly increased over the past fifty years and this has led to an increased risk of ageing associated disability in mental and neurological functions ${ }^{1}$. With the increase of elderly population in Bangladesh, as in most Western countries, the detailed examination and assessment of cognitive function have become a necessary one ${ }^{1}$. However, the exact evaluation of cognitive impairment is often difficult, especially among the elderly. Among the battery of screening tools available, mini mental state examination (MMSE) had been most widely used ${ }^{2-4}$. It has been modified and translated into many languages, including Chinese and Finnish ${ }^{5}$, Korean ${ }^{6}$, Japanese ${ }^{7}$, Spanish $^{8}$, Hindi ${ }^{9}$ etc. Alhough MMSE had been universally used as screening instrument, it has got some limitations in terms of its sensitivity and confounding biases with regard to education, ${ }^{10}$ and culture and language ${ }^{11,12}$. In 1988, Jorm and colleagues ${ }^{13}$ published an analysis addressing MMSE bias by level of education among a sample of elderly population using methods outlined in Berk's Handbook of Methods for Detecting Test Bias. So there has been an increasing need for development of a neuropsychiatric tool that effectively identifies the cognitive deficit among Bangladeshi adult population.

MMSE have been extensively studied for their reliability, validity and correlation with other psychometric tests. It has a higher interrater reliability ${ }^{14}$ and sensitivity and scores correlating well with the degree of cortical atrophy observed on the brain CT scan ${ }^{15}$ and also with results of other tests ${ }^{16,17}$. However, there are a number of intrinsic problems which make it difficult to use with people from non western social and cultural backgrounds. The illiterate cannot perform two of the test items (e.g. 'write a sentence' and 'close your eyes') and in some languages there are no phrases or words such as 'no ifs, ands or buts' and 'WORLD', which makes translation from English difficult. Test performance is also influenced by demographic factors ${ }^{18,19}$. The literacy rate in Bangladesh ${ }^{1}$ is only $59.82 \%$ (including those who can just write their names). It is therefore often difficult to apply MMSE appropriately in such group of people. Many of them cannot calculate up to 100 , do not follow English calendar, can't make sentences or spell the words backward. These limitations led us to develop a modified Bangla version of MMSE for our people.

\section{Methods:}

Study type and sample: This is a descriptive type of observational study carried out in weekly neurology outdoor clinic of Department of Neurology, Dhaka Medical College Hospital, Dhaka, from January to December of 2013. A total of 200 healthy adults (patient attendants at the clinic) who met the inclusion criteria, were interviewed using a structured questionnaire containing information on age, sex, residence, educational backgrounds and questions set at MMSE-E and modified Bangla questions for MMSE-B (Fig.-1). The literate people we asked whether they were comfortable to answer in English or they would like the translated form (MMSE-T) and we applied the form of MMSE according to their wish. But in other group of people the modified Bangla version (MMSE-B) was used irrespective of level of education.

\section{The inclusion criteria:}

1. Both the male and female, above 50 years of age;

2. Willing to cooperate;

3. Able to give informed consent;

4. No evidence of any diagnosed psychiatric disorder (past or present);

5. No problem suggestive of organic pathology (due to head injury, seizure, mental retardation or substance abuse);

6. No problems with speech, hearing or vision, which would impede the conduct of examination.

\section{Exclusion criteria:}

1. Uncooperative persons;

2. Diagnosed case of psychiatric disorder or comorbid condition;

3. Having any significant organic pathology like head injury, seizure, mental 
retardation, substance abuse, etc., or having physical health problems which affects activities of daily living during past one year;

(4) Having problems with speech, hearing, and vision, which can impede the interview.

The tests were performed by experienced neurologists, from consultants up to the level of professors.

Tools: The MMSE-E and MMSE-B were applied to 200 different healthy adults. For systemic application the MMSE was translated to Bangla from the English version and then retranslated back to English for the check of consistency by atleast three experts. The Bangla Modification of MMSE was done by the "Technical Committee for the Development of MMSE in Bangladesh" and approved by the "Committee for the Development of MMSE in Bangladesh." Lastly the best translated form of MMSE and the modified Bangla MMSE was applied and pretested.

\section{Test Modifications:}

Orientation to time: In the English MMSE, a point each is given for correctly named day, date, month, year and season, for a total of five points. But elderly Bangladeshi people usually do not know or keep track of years in the Roman calendar. So keeping the option open for Bengali calendar, we have included seasons like summer, winter and rainy season etc as an alternative. Thus, the five final items are: day, date, month, year and season.

Orientation to place: In MMSE-E, five questions are asked, which could include "name of this place/building', floor (storey), street address, city, county, state and country. It was difficult to identify five appropriate spatial orientation questions for our sample. Buildings in the villages neither have street numbers nor do the streets have names. So we have finally selected 'country', 'district', 'city', 'name of interview place' and 'floor'.

Registration: In the MMSE-E, the names of three objects are given. We opted for words equivalent in familiarity to 'apple, table, and penny' used in the MoVIES ${ }^{20,21}$ project. But tables are not ubiquitous pieces of furniture in the rural setting. So we simplified the words to 'Banana', 'a bird' and 'taka'. In bangle Taka means the currency or the penny.

Attention: The MMSE-E has two alternative attention subtests: (i) backwards spelling of WORLD and (ii) serial subtractions of seven starting at 100 . These two tasks require that the subject be able to keep his attention on a specific problem for a period of time, maintain a set of response and have sufficient working memory to hold and manipulate few pieces of information in mind while solving a multistep problem. As most of our people are illiterate, spelling either forwards or backwards is never an option. We also have changed the mental arithmetic to a deduction of seven from thirty. We gave the subtraction task in the form of a story: A man has 30 cows, if he sells seven of them, how many will remain and if he sells seven in the next month, how many will be there, in the farm and so on.

Recall: The subject is asked to recall the three objects (banana, bird and taka) named earlier.

Naming: As in the English version, the subjects are shown a wristwatch and asked to name it. As a second object we used was a pen rather than a pencil. Because, the ball-point pens are the more familiar objects than pencil and there was chance of confusion between a pen and pencil.

Repetition: In English, the standard phrase for repetition is No ifs, ands or buts'. This is also a test of fluency. Patients with non-fluent aphasia find repetition particularly difficult as it requires connecting the words with preposition and making appropriate word without grammatical errors. Our technical committee came to a consensus about a Bangla phrase ' ek maghe shit jai na' meaning 'one swallow does not make a summer'.

Visual command (read and follows command): In the English version, the subject is shown a written command 'Close your eyes' and asked to do as it says. For our mostly illiterate subjects, we have excluded the written part of the test. Here the examiner says 'Look at me and do exactly what I do' and then closes his own eyes for 2 seconds (follow example), while 
the co-examiner observes and records the subject's response.

Three-step task: We haven't changed this task at all. As in the English version, the subject is asked to pick up (or take) a given piece of paper with his right hand, fold it in half with both hands and give the paper back to the examiner, with a point being given for each step remembered and correctly executed.

Making a sentence: This is a task with immense difficulty for most of our patients. In the English version, the subject is asked to write a complete sentence and is given a full point if the sentence has a subject and a predicate, regardless of spelling, grammar and syntax. We asked them to tell us something about the surroundings. In some cases we had to give some clues.

Copying a figure: We knew that any task involving paper and pencil would be unfamiliar and intimidating to our patients. In the original MMSE, the subject is asked to copy a figure consisting of two intersecting pentagons. A point is awarded only if there are 10 angles and two of them intersect. We thought that the intersecting pentagons will be too difficult for these subjects to copy and therefore substituted with a simpler figure (three circles connecting one another).

Ethical Clearance: The present study was approved by the Ethical Review Committee of Dhaka Medical College, Dhaka.

\section{Results:}

Demographic characteristics: The demographic characteristics of both groups of study subjects are shown in table- 1 . There was no significant difference (Chi-Square value= 3.383 , $p$ value $>0.05$ ) in study subjects between these two groups except for the level of education ( $p$ value $<0.05$ ). In subjects older than 50 years, the mean age at presentation was $58.1 \pm 7.8$ and $94 \%$ were within $50-70$ years of age. Male were more common $(80,66)$ in both the groups and most belongs to rural areas (72, 62). The subjects up on whom MMSE were employed had higher level of education than those of MMSE-B. MMSE-B were mostly employed on people having only primary level of education (up to class five, $n=80$ ) or no education $(n=2)$, whereas MMSE were employed up on people having a level of education higher than class five $(n=96)$.

Consistency of questions: The mean score of each question in every item of MMSE and MMSE-B along with their correlation coefficient are shown in Table-2. Every question in each item of cognitive domain was correlated well (correlation co-efficient range from $0.801-0.971$ ) except the $7^{\text {th }}$ (correlation co-efficient 0.418). The mean score for this question was higher among subjects answering MMSE-B than those of MMSE (0.90 versus 0.54). The mean score of MMSE-B was greater than the mean score of MMSE for most of questions except the $1^{\text {st }}$ question that is related to orientation of time. The mean of total score in MMSE-E and MMSE-B were 24.04 and 24.91 respectively with a correlation co-efficient of 0.940 .

\section{Discussion:}

It is of immense importance that the MMSE applied should be appropriate in regard to its subjects and items studied in a specified segment of population in relation to their language and socio-cultural background. Henceforth, MMSE had been translated and or modified in different languages. Our endeavor was also to test the applicability of Bangla version of MMSE. Our study result has both qualitative and quantitative implications. Our data suggests that carefully modified Bangla version i.e. MMSE-B is not only effective as MMSE for most of the cognitive domain assessed but also even better in some segments. Irrespective of level of literacy our subjects were also more comfortable with MMSE-B.

In this study, MMSE was adapted into MMSE-B in order to meet two goals: (1) to be consistent with Bangladeshi cultural contexts and (2) feasible for use in illiterate and less educated elderly. The original MMSE ${ }^{2}$ contains 12 items with a possible score ranging from 0 to 30 . Two items are reading and writing dependent: reading and following command 'Close your eyes' and writing a sentence, both of which are not possible to perform among illiterate or less 
educated. These two literacy dependant items were replaced by saying something about the surroundings. Also the calculation segment was simplified by serial subtraction of 7 from 30.

In this study, subjects answering MMSE-E scored better in the $1^{\text {st }}$ question related to orientation of time. This is probably due to the fact that English calendar much frequently and commonly used by the people in general in Bangladesh than the local Bengali calendar that is relatively more used by the farmers.

All the other questions correlated well with MMSE except the $7^{\text {th }}$ questions which was even better in MMSE-B. This is due to the fact that in the seventh question the English phrase "No Ifs, and, or buts were replaced by familiar Bangla phrase that has helped in understanding and repeating. Irrespective of level of literacy, the questions in MMSE and MMSE-B correlated well individually and also with the mean of total score. Interestingly in this study, subjects scored better in all other questions (except the $1^{\text {st }}$ one) while answering MMSE-B than MMSE. This is consistent with the study of Tiwari et $\mathrm{al}^{22}$, Ganguli et $\mathrm{al}^{9}$, Das et $\mathrm{al}^{12}$. All these studies were done among Hindi speaking people either in India or abroad. The modification done was also similar to our study and they also modified the questions in relation to local cultural context and adapting to illiterate people either in rural or urban areas. Geographically Bangladesh share common border with India except in the south and also share a similar socio-cultural background with the people of India. So it is not unlikely to get similar results of these study findings. $\mathrm{Xu} G$ et $\mathrm{al}^{23}$ conducted a study in China with Chinese adapted MMSE (CAMSE) up on both literate and illiterate people with dementia and without dementia. They showed that CAMSE was feasible to use in clinical dementia screening. Similarly Jeong SK et $\mathrm{al}^{24}$ showed that Korean version of MMSE (KmMMSE) was useful and reliable. These results prove the usefulness of developing culturally adaptable version of MMSE in ASIA.

Literatures $^{25,26}$ suggest that lower levels of education are associated with higher prevalence of dementia and that lack of education may be a risk factor for Alzheimer's disease. If there is a genuine difference in risk, one would expect to find higher prevalence rates of Alzheimer's diseases in societies with lower educational levels, perhaps in pandemic proportions in subgroups with no education. It is therefore a methodological challenge to develop appropriate cognitive tests for uneducated and illiterate populations. Our endeavor was to simplify the test as far as possible in context of Bangladesh as well as to keep this modified version at least as effective as MMSE for use in screening purpose.

We had several limitations in the study. First of all, the number of subjects is small. Secondly, this is a single centre experience which may not represent the whole country. However the issue of representativeness is a bit minimized by using Dhaka Medical College Hospital which is the largest tertiary level hospital in the country and receives people from all over the country. Finally, there is chance of inter observer variability in assessing the MMSE.

\section{Conclusion:}

MMSE-B correlates well with MMSE-E as per individual question and also in total score. The test results are even better in MMSE-B in some segments of cognitive assessment. So MMSE$\mathrm{B}$ is comparable to MMSE and even better is some instances for use in Bangladeshi people irrespective of level of literacy.

\section{References:}

1. Rahman NM, Kamal GM. eds. Socio-economic and Demographic Report: Population and Housing Census 2011. Dhaka: Bangladesh Bureau of Statistics; 2011. National Series, Vol 4.

2. Folstein MF, Folstein SE, McHugh PR. 'Minimental state': a practical method of grading the cognitive state of patients for the clinician. J Psychiutr Res 1975; 12: 189-98.

3. Diniz BSO, Yassuda MS, Nunes PV, et al. Minimental State Examination performance in mild cognitive impairment subtypes. Int Psychogeriatrics 2007; 19: 647-56.

4. Nakasujja N, Musisi S, Walugembe J, Wallace D. Psychiatric disorders among the elderly on nonpsychiatric wards in an African setting. Int Psychogeriatrics 2007; 19: 691-704. 
5. Salmon DP, Riekkinen PJ, Katzman R, et al. Cross-cultural studies of dementia: a comparison of MMSE performance in Finland and China. Arch Neurol 1989; 46: 769-72.

6. Park, J. H. and Kevon, Y. C. Modification of the MMSE for use in the elderly in a non-Western society. Part I. Development of Korean version of MMSE. Int J Geriatr Psych 1990; 5: 381-7.

7. Larson E. The Ni-Hon-Sea Project: an overview. In: Curb JD, Graves AB. eds. Multi-national Epidemiological Studies of Dementia (symposium abstract). Gerontologist 1992; 32(Suppl. 2): 219.

8. Loewonstein DA, Arguelles T, Barker WW, Duara R. A comparative analysis of neuropsychological test performance of Spanish-speaking and English-speaking patients with Alzheimer's disease. J Gerontol 1993; 48: 142-49.

9. Ganguli, M, Ratclif G, Chandra V. A Hindi version of the MMSE: the development of a cognitive screening instrument for a largely illiterate rural elderly population in India. Int $\mathrm{J}$ Geriatr Psych 1995; 10: 367-77.

10. Jones RN, Gallo JJ. Education bias in the Minimental State Examination. Int Psychogeriatrics 2001; 13: 299-310.

11. Shulman KI, et al. IPA survey of brief cognitive screening instruments. International Psychogeriatrics 2006; 18: 281-94.

12. Das SK, Banerjee TK, Mukherjee CS, et al. An urban community-based study of cognitive function among non-demented elderly populations in India. Neurology Asia 2006; 6 (11): 37-48.

13. Berk RA. Handbook of Methods for Detecting Test Bias. Baltimore: Johns Hopkins University Press, 1982.

14. Anthony JC, LeResche L, Niaz U, et al. Limits of the 'minimental state' as a screening test for dementia and delirium among hospital patients. Psycho Med 1982; 12: 397-408.

15. Tsai L, Tsuang, MT. The mini-mental state test and computerized tomography. Am J Psychiut 1979; 136: 436-38.

16. Thal LJ, Grundman M, Golden R. Alzheimer's disease: A correlational analysis of the Blessed information-memory-concentration test and the mini-mental state exam. Neurology 1986; 36: 262-4.
17. Fillenbaum GG, Heyman A, Wilkinson WE, Hayness CS. Comparison of two screening tests in Alzheimer's disease: The correlation and reliability of the mini-mental state examination and the modified Blessed test. Arch Neurol 1987; 44: 924-8.

18. Escobar JI, Burnam A, Karno M, et al. Use of the mini-mental state examination (MMSE) in a community population of mixed ethnicity: cultural and linguistic artifacts. J Nerv Ment Dis 1986; 174: 607-14.

19. Fillenbaum GG., Hughes DC, Heyman A, et al. Relationship of health and demographic characteristics to Mini-Mental State Examination score among community residents. Psychol Med 1988; 18: 719-26.

20. Ganguli M, Belle S, Ratcliff G, et al. Sensitivity and specificity for dementia of population based criteria for cognitive impairment: The MOVIES Project. J Gerontol Med Sci 1993; 48(4): 152-61.

21. Ganguli M, Seaberg E, Belle S, et al. Cognitive impairment and the use of health services in an elderly rural population: The Mo-VIES project. J Am Geriatr Soc 1993; 41(10): 1065-70.

22. Tiwari SC, Tripathi RK, Kumar A. Applicability of the Mini-mental State Examination (MMSE) and the Hindi Mental State Examination (HMSE) to the urban elderly in India: a pilot study. Int Psychogeriatrics 2009; 21: 123-8.

23. XU G, Meyer GS, Huang Y, et al. Adapting MiniMental State Examination for dementia screening among illiterate or minimally educated elderly Chinese. Int $\mathrm{J}$ Geriatr Psychiatry 2003; 18: 609-16.

24. Jeong SK, Cho KH, Kim JM. The usefulness of the Korean version of modified Mini-Mental State Examination (K-mMMSE) for dementia screening in community dwelling elderly people. BMC Public Health 2004, 4: 31.

25. Mortimer JA, Graves AB. Education and socioeconomic determinants of dementia and Alzheimer's disease. Neurology 1993; 43(Suppl. 4): S3944.

26. Katzman R. Education and the prevalence of dementia and Alzheimer's disease. Neurology 1993; 43: 13-20. 